\title{
Application of Educational Gaming and Robotics in Teaching and Learning Process
}

\author{
Dr. Stella N. Nwigbo* \\ Computer Science Department \\ School of Secondary Education (SC) \\ Federal college of Education (T), Omoku \\ Rivers State. \\ *Ekine-pakaye Adline Chidinma \\ Computer Science Department \\ School of Secondary Education (SC) \\ Federal College of Education (T), Omoku \\ Rivers State. \\ *Seji Happy Alfred \\ Computer Science Department \\ School of Secondary Education (SC) \\ Federal College of Education (T), Omoku \\ Rivers State.
}

Abstract: The development of technology has resulted in the development of many assistive tools employed to facilitate education. Amongst these technologically enhanced tools developed for education are games and robots. This paper examines the application of educational games and robots through review of available literature. The areas of application of games and robots in education have been presented. The paper further highlights some challenges encountered in the deployment of games and robotics in education.

Key Words: - Creativity, Computer Simulation, Autonomy, Flexibility, Collaboration.

\subsection{INTRODUCTION}

This paper presents the application of games and robotics in education. The importance of games and robots are equally presented. The paper continues by addressing some challenges involved in the application of games and robots in education.

Games and robots are implemented in education as assistive tools to facilitate learning processes. There are varying cognitive abilities between students. This therefore, affects their learning adaptation. A wide variety of technological applications have been developed to support the students at varying levels of academic domains. Such technologies include robots, game apps and computer simulations (D'mello\&Graesser, 2013).
Alcorn (2003) defined game as "kind of sports or entertainment that requires participation, competition with oneself or with other rivals to achieve certain goals and have special rules." Educational games on the other hand, are software that help students to learn lesson subjects and to develop their problem solving skills by using their desire and enthusiasm to play (Cankaya\&Karamete, 2008). Games in education provide for an interactive strategy in education and are capable of developing students' skills areas such as creativity, flexibility, autonomy, collaboration and responsibility (Pontes 2013).

De Freitas (2006) noted that the learning processes are not controlled entirely by the games when applied in education. 
Learning activities such as feedbacks and reflections relate to topics treated in the games are required.

Prensky (2003) noted that young people are motivated towards games and often lack interest in educational contents. Fracer (2003) noted that this interest in games shapes their cognitive abilities and interests in learning which sometimes, make formal education meaningless to them. Prensky (2003), however, noted that the motivation in games could be combined with educational contents to further capture the interests of young people. He proposed Digital Game-Based Learning as a tool to achieving this.

Games that incorporates educational objectives and subjects are capable of making academic learning easier, enjoyable, interesting, learner-centered and more effective (Kafai, 2001). The interest in educational games could vary along gender line. This shows that gender preference could affect the use of educational games. Empirical research, however limited, on the use of games in education, showed that male and female genders prefer different kinds of game with male playing more games and for longer period than the female (McFarlane et al, 2002).

Robots are physical and autonomous artifacts with capabilities of interacting and communicating with humans through human social mechanisms such as natural speech and social cues (Brazeal, 2003). Benitti (2012) noted that robotics technology is a fashionable tool for education of students in middle and high schools. Significant development have been recorded in the design of social robots applied in education which include areas such as its anthropomorphic, morphologic and technical capabilities (Disalvo et al, 2002).

Robotics have been implemented in education in varying areas ranging from social assistive tools to advance learning tools. Some robots operate incorporating games, videos and many other mechanisms.

\subsection{RELATED WORKS}

Educational games have been developed to help health professionals to acquire skills necessary to perform professional task as developed by Andrew (2011). Hou\& Chou (2012) developed digital game that supported physics students to learn complex topics such as electromagnetism. Pontes et al (2020) developed an educational, turn-based, cross-platform, visual-based and touch-ready digital game that helped teach children and adults how to learn signs in Brazilian Sign Language (BSL). The game, MatLIBRAS promotes the deaf culture and is capable of using other sign language other than the Brazilian sign language.
The learning effectiveness and motivational appeal of computer based game on the learning of computer memory concepts was examined by Papatergiou (2009). The game based learning application was designed in accordance with Greek high school computer science curriculum. This study was done in comparison with a similar application having similar content but lacking the game aspect. Result obtained showed that gaming approach was more effective than the non-game approach in the promotion of student's knowledge in computer memory concepts. The researchers furthermore, recommended the use of computer games for the motivation of students in learning.

The effectiveness of educational game in the improvement of arithmetic skill in children was examined by Casteller et al (2014). The results obtained showed that the use of games for arithmetic is beneficial for both cognitive and affective learning outcomes.

A social assistive robot, KindSAR was developed by Friden (2014) for the education of preschool children. The tool was developed to provide assistance to teachers by engaging kids through educational games by storytelling. In its application, the teacher is provided with detailed feedback on the children's performance with game task. The tool showed unique results as it was capable of facilitating constructive learning through storytelling and teaching of new motor skills and concepts. The development of KindSAR however, contrast the position of Benitti (2012) that posited that robotics in education is applied to teaching children in middle and high school.

Chang et al (2010) in their investigative study on the influence of robots on authentic learning experience of students, designed a mixed-reality based robot, RoboStage to ease authentic learning amongst junior high school children. Results obtained from experiment showed that the use of RoboStage significantly improved the sense of authenticity of the task performed by students and positively affected learning motivation of the students in learning.

Chen et al (2020) developed a novel bi-directional childagent peer learning robot that compared the impacts of tutor, tutee and peer agents on the learning and affect of children. Fifty-nine children between ages $5-7$ were used in the study. Results of the study revealed that the children's vocabulary were improved while using the robot as a tutor and a greater affect was exhibited by the children when the robot served as their tutee. Therefore, both cognitive and emotional needs of the students were improved with the use of robot as a peer agent. 


\subsection{APPLICATIONS OF GAMES AND ROBOTICS IN EDUCATION}

The application of robots have grown from fields to fields. Earlier applications of robots were in industrial manufacturing and lacked humanoid features. Recently, the application of robots have been seen in various domains including education (Breazeal, 2014).

Robotic application in education aids in improving problem solving, logic and scientific inquiry (Friden, 2014). Robots application in education serve as IntelligentTutoring System (ITS). ITS is a field with use of computer for instructions, feedback and students guides (D'mello\&Graesser, 2013). ITS is capable of assessing students' mastery of knowledge as noted by Baker et al (2010), modelling of students cognitive states (Cobett et al, 2010), patterning or adapting the learning contents to individual needs as noted by Manickam (2017) and also capable of capturing students affect and motivations (D'mello\&Graesser, 2013).

Social assistive robots have been applied in the education of people with special needs/vulnerable people. Heerink et al (2008) noted that social assistive robots have been implemented in the education of elderly patients while Shukla-Mehta et al (2011) noted their application in teaching children with autism. Also, social assistive robotics have been implemented in child care and studies have shown its positive impact on the development of children with social disorders (Kozima et al, 2004; Tanaka et al, 2006).

Gordon et al (2016) and Kory-Westlund (2019) from their works, noted that social robots are capable of eliciting rich social behaviour from students and enhance their engagement and learning due to its attentive and expressive co-present behaviours. Many social assistive robots such as KindSAR developed by Friden (2014) are capable of regulating and monitoring the cognitive development of children over time and provide unique data on children's performance to aid teachers' evaluation.

Social robots have helped students learn various skills through gaming (Movellan et al, 2009). Also, social robots have been applied as a tutee where it is used to interact with students as a learner (Chin et al, 2013). In this approach, the robot is useful in the estimation of the students' abilities and helps in the personalization of students' learning content appropriate to the student knowledge level (Park \& Howard, 2015). Tanaka \&Matsuzoe (2012) however, noted that the use of social robots as tutee without involvement of a human teacher to instruct may hinder students learning especially children. Further application of social robots has been applied in reciprocal peer interaction (Howard et al, 2017; Ros et al, 2016).

Educaitonal games are implemented to motivate students' interests in learning activities of students. Games enhances the affective appeal of students towards learning as presented by Papatergiou (2009). Also, games have been developed to improve the skills of students in their curricula contents. Educational games have been implemented to improve arithmetic skills of students, improve their memory in learning complex subjects in science, technology, engineering and medicine.Important concepts such as algorithms, programming and data structure could be learnt by application of digital games.

Kolb (1984) noted that educational games are developed to make students active in learning, reflect on their performance by considering their weaknesses and strength and develop plan for their future actions. Educational gaming allows for large volume of materials to be covered within a single activity(Boctor, 2013).

Digital games have been employed to teach students with disabilities. Pontes et al (2020) developed a game capable of teaching students that were deaf the Brazilian Sign Language. The game was also capable of incorporating other sign languages.

\subsection{CHALLENGES IN THE USE OF EDUCATIONAL GAMES AND ROBOTS}

Despite the huge capabilities shown by robotics in education in the facilitation of teaching and learning, research have shown that the use of robots in education remains insufficient. This is hugely affected by the acceptance of the technology by teachers. Buabeng-Andoh (2012) however, noted that the acceptance of the use of robots in education is affected by factors such as user characteristics, content characteristics, technological considerations and organizational capacities.

Friden\&Belokopytov (2014) carried out a methodical research in the acceptance of socially assistive robotby preschool and elementary school teachers in a workshop they organized. From the study, a positive acceptance was demonstrated by the participants of the workshop towards social assistive robots. This acceptance was due to the level of exposure of the participants of the workshop. In other settings, a less positive acceptance was observed.

The use of robot in education is faced with a challenge of breakdown in interaction between robots and their users. Serholt (2018) in her study investigating the causes of breakdown in the interaction between children and robotic tutor, revealed that the likely causes could be due to any of 
the following four reasons; lack of consistency and fairness, robots inability to evoke initial engagement and identify misunderstanding, confusing scaffolding and problems with control.

Tusan et al (2008) highlighted that some disadvantages exist in the use of games in education despite huge advantages it presents. In their work, they argued that the use of games in education requires heavy investment, orientation process, more time than the traditional method of learning and could cause the students to spend more time with game activities other than educational purposes.

The challenges presented above could be mitigated through improved design of games and robots. The design of robots should consider aspect that engages the users properly to avoid breakdown. Also, the incorporation of games into learning should be used such as it could not consume more of the affect and time of users.

\subsection{CONCLUSION/ FUTURE FRAMEWORK}

This paper examined from literature the application of games and robots in education. In the paper, games and robots have been revealed to be great assistive educational tools that have been deployed in various areas of education. From the paper, educational games and robots have been revealed to be capable to;

- Capture students affect and motivation to learning and make students active in learning.

- Improve the problem solving skills of students.

- Assessment of students' knowledge and model their cognitive states.

- Education of both elderly and young learners.

However, the incorporation of games and robotics in education is posed with some challenges. The literature examined in this paper revealed that the use of robot and games in education is posed requires heavy investment and is time consuming. Also, the deployment of robot could result in breakdown in interaction between the robots and their users. The use of robotics in education has not been generally accepted.To overcome the above mentioned challenges, it is highlighted in the paper the use of optimized design of specific games and robots to addressing the challenge.

\section{REFERENCES}

[1]. Alcorn, P. (2003) Social issues in technology: A format for investigation (4 ${ }^{\text {th }}$ Edition) Pearson Education: New Jersey.

[2]. Andrews, A. (2011) Serious games for psychological health education. International Conference on Virtual and Mixed-Reality (pp. 3 - 10), Berlin, Heidelberg: Springer.

[3]. Baker, R. S. T. D., Cobert, A. T., Gowda, S. M., Wagner, A. Z., MacLaren, B. A., Kauffman, L. R. et al (2010) Contextual slip and prediction of student performance after use of an intelligent tutor. In P. De Bra, A Kobsa, D. Chin (Eds), user modelling, adaptation and personalization (52 -63), Berlin, Heidelberg: Springer Berlin Heidelberg.

[4]. Benitti, F. B. V. (2012) Exploring the educational potential of robotics in schools: a systematic review. Computer \& Education, 58(3), 978 - 988.

[5]. Boctor, L. (2013) Active-learning strategies: The use of a game to reinforce learning in nursing education: A case study. Nursing Education Practice, 13(2), 96 - 100.

[6]. Breazeal, C. L. (2014) Social interactions in HRI: The Robot View. IEEE Transactions on Systems, Man and Cybernetics, Part C (Applications and Reviews), 34 (2), $181-186$.

[7]. Buabeng-Andoh C. (2012) Factors influencing teachers adoption and integration of information and communication technology into teaching: A review of the literature. IEDICT, 8, $136-155$.

[8]. Cankay, S. \&Karamete, A. (2008) The effects of educational computer games in students attitudes towards Mathematics course and educational computer games. Mersin University, Journal of the Faculty of Education, 2, $116-127$.

[9]. Chang, C.-W., Lee, J.-H., Wang, C.-Y. \& Chen, G.-D. (2010) Improving the authentic learning experience by integrating robots into the mixed-reality environment. Computers \& Education, 55, 1572 - 1578.

[10].Chen, H., Park, H. W. \&Breazeal, C. (2020) Teaching and learning with children: impact of reciprocal peer learning with a social robot on children's learning and emotive engagement. Computers \& Education,150, xxx.

[11].Chin, D., Dohmen, I. \& Schwartz, D. (2013) Young children can learn scientific reasoning with teachable agents. IEEE Transactions on Learning Technologies I, $6,248-257$.

[12].Corbett, A., Kauffman, L., MacLaren, B., Wagner, A. \& Jones, E. (2010) A cognitive tutor for genetics problem solving: Learning gains and students modelling. Journal of Educational Computing Research, 42 (2), 219- 239.

[13].D'mello, S. \&Graesser, A. (2013) Autotutor and affective autotutor: Learning by talking with cognitively and emotionally intelligent computers that talk back. ACM Transactions on Interactive Intelligent Systems, 2 (4), $1-23$.

[14].De Freitas, S. (2006) learning in immersive worlds: A review of game-based learning.

[15].Disalvo, C. F., Gemperle, F., Fortilizzi, J. \&Kiesler, S. (2002) All robots are not created equal: The design and perception of humanoid robot heads. In Proceeding of the $4^{\text {th }}$ Conference on Designing Interactive Systems: Processes, practices, methods and techniques (pp. 321 326). 
[16].Facer, K. (2003). Computer games and learning. [https://www.futurelab.org.uk/resources/documents/discu ssion_papers/Computer_Game_and_Learning_discpaper. pdf ]

[17].Friden, M. (2014) Storytelling by a kindergarten social assistive robot: A tool for constructive learning in preschool education. Computers \& Education,70, 53 64.

[18].Friden, M. \&Belokopytov, M. (2014) Acceptance of socially assistive humanoid robot by preschool and elementary school teachers. Journal of Computers in Human Behaviour, 33, 23 - 34.

[19].Gordon, G., Spaulding, S.,Westlund, J. K, Lee, J. J., Plummer, L., Martinez, M. (2016) Affective personalization of a social robot tutor for children's second language skills. In Proceedings of the $30^{\text {th }}$ Conference on Artificial Intelligence.

[20].Heerink, M. Krse, B., Evers, V., \&Wielinga, B. (2008) Response to a social robot by elderly users. Intelligent Robots and System, 2724.

[21].Hou, H. T. \& Chou, Y. S. (2012) Exploring the technological acceptance and flow state of a champer escape game. Escape the Lab for learning electromagnetism concept. ICCE, 38.

[22].Howard, C., Jordan, P., Di Eugenio, B. \& Katz, S. (2017) Shifting the load: a peer dialogue agent that encourages its human collaborator to contribute more to problem solving. International Journal of Artificial Intelligence in Education, xxx.

[23].Kafai, Y. (2001) The educational potential of electronic games: From games-to-teach to games-to-learn. [https://www.culturalpolicy.uchicago.edu/conf2001/pape rs/kafai.html]

[24].Kolb, D. A. (1984) Experiential learning: Experience as the source of learning and development. Prentice-Hall, Englewood Cliffs, NJ.

[25].Kory-Westlund, J. M., Jeong, S., Park, H. W. Ranford, S. Adhikari, A., Harris, P. L. et al (2017) Flat vs. expressive storytelling: Young children's learning and retention of a social robots narrative. Frontiers in Human Neuroscience, 11, 295.

[26].Kozima, H., Nakagawa, C., \& Yano, H. (2004) Can a robot empathize with people? International Journal of Artificial Life and Robotics, 8, 83-88.

[27].Manickam, I., Lan, A. S. \&Baraniuk, R. G. (2017) Contextual multi-armed bandit algorithms for personalized learning action selection. In 2017 IEEE International Conferenceon Acoustics Speech and Signal Processing (pp. 6344 - 6348).

[28].McFarlane, A., Sparrowhawk, A. \&Heald, Y. (2002) Report on the educational use of games. [https://www.teem.org.uk/publications/teem_gamesined_ full.pdf]

[29].Movellan, J. R., Eckhardt, M. \& Rodriguez, A. (2009) Sociable robots improves toddler vocabulary skills. In $20094^{\text {th }}$ ACM/IEEE International Conference on Human-Robot Interaction (pp. 307 - 308).
[30].Papastergiou, M. (2009) Digital game-based learning in high school computer science education: Impact on educational effectiveness and student motivation Computers \& Education, 52, 1 - 12.

[31].Park, H. W. \& Howard, A. M. (2015) Retrieving experience: Interactive instance-based learning methods for building robot companions. In 2015 IEEE International Conference on Robotics and Automation (pp. 6140-6145).

[32].Pontes, H. P. (2013) Desenvolvimento de Jogos no Processo de AprendizadoemAlgorithmos e Programmacoco de Computadores. Proceeding of the XII SimposioBrasileiro de Games e Entretentmento Digital (SB Games) (pp. 220 - 228). SBC.

[33].Pontes, H. P., Duarte, J. B. F. \&Pinheiro, P. R. (2020) An educational game to teach numbers in Brazilian Sign Language while having fun. Computer in Human Behaviour, $\mathrm{xxx}$.

[34].Prensky, M. (2003) Digital game-based learning. ACM Computers Entertainment, 1(1), 1 - 4 .

[35].Ross, R., Oleari, E., Pozzi, C., Sacchitelli, F., Baranzini, D. \&Bagherzadhalimi, A. (2016) A motivational approach to support healthy habits in long-term childrobot interaction. International Journal of Social Robots, $\mathrm{xxx}$.

[36].Serholt, S. (2018) Breakdowns in children's interaction with a robotic tutor: A longitudinal study. Computers in Human Behaviour, 81, 250 - 264.

[37].Shukla-Mehta, S., Miller, T., \& Callahan, K. T. (2009) Evaluating the effectiveness of video instructions on social and communication skills training for children with autism spectrum disorders; a review of the literature. Focus on Autism and other Developmental Disabilities Journal, 25, 23 - 26.

[38].Tanaka, F. \&Matsuzoe, S. (2012) Children teach carereceiving robot to promote their learning: Field experiments in a classroom for vocabulary learning. Journal of Human-Robot Interaction, xxx.

[39].Tanaka, F., Movellan, R., Fortenberry, B. \&Aisaka, K. (2006) Daily HRI evaluation in a classroom environment. In Human-Robot Interaction, xxx.

[40].Tusan, H., Arkun, S., Bayirtepe-Yagiz, E., Kurt, F., \&Yermeydan-Ugur, B. (2008) Evaluation of computer games for learning about mathematical functions. Imanger's Journal of Educational Technology, 5(2), 64 72. 